\title{
Determination of Trace Elements in Quartz by Combined EPMA and CL Microspectrometry
}

\author{
K. Goemann ${ }^{1}$, O. V. Vasyukova ${ }^{2,3}$, V. S. Kamenetsky ${ }^{2}$, C. M. MacRae ${ }^{4}$, N. C. Wilson ${ }^{4}$ \\ ${ }^{1}$ Central Science Laboratory, University of Tasmania, Hobart, TAS 7001, Australia \\ ${ }^{2}$ ARC Centre of Excellence in Ore Deposits, University of Tasmania, Hobart, TAS 7001, Australia \\ ${ }^{3}$ Department of Earth and Planetary Sciences, McGill University, Montreal, QC H3A 9E8, Canada \\ ${ }^{4}$ CSIRO Process Science and Engineering, Clayton, VIC 3169, Australia
}

Quartz eyes from different porphyry deposits were studied by electron probe microanalysis (EPMA) and hyperspectral cathodoluminescence (CL) mapping to determine their origin. These "eyes" are mm-sized crystals, which are commonly referred to as phenocrysts but in many cases may have formed after magma emplacement.

Ti concentrations were determined on a JEOL JXA 8500F EPMA at $20 \mathrm{kV}$ accelerating voltage, $200 \mathrm{nA}$ beam current and $20 \mu \mathrm{m}$ beam diameter, using two spectrometers with PET crystals in parallel and counting for 80 seconds on peak and 40 seconds each on two backgrounds, resulting in a detection limit of $10 \mathrm{ppm}$ at $99 \%$ confidence. Further $\mathrm{Ti}$, Al, and Fe measurements were performed on a Cameca SX100 EPMA at $15 \mathrm{kV}, 200 \mathrm{nA}, 5 \mu \mathrm{m}$, with counting times of $300 \mathrm{~s}$ for peak and $150 \mathrm{~s}$ each for two backgrounds. One LPET crystal was used fo Ti, two TAP for Al, and two LLiF for Fe, leading to detection limits of 12, 7, and 19 ppm respectively. Averages of 3 spots co-located in bands with similar panchromatic CL intensity were used where possible to improve the analytical precision. Due to a known background hole beneath the Ti Ka peak when using PET crystals [1], a blank correction was performed using the ultra pure silica glass Spectrosil 1000 (Saint Gobain). The blank correction was consistent over 17 analysis sessions spanning 15 months with $+16 \pm 2 \mathrm{ppm} \mathrm{Ti,}-27 \pm 4 \mathrm{ppm} \mathrm{Al}$, and -9 \pm 8 ppm Fe. Hot Springs Quartz (Harvard 122838, [2]) yielded long term averages of $2 \pm 3$ ppm Ti, $34 \pm$ $6 \mathrm{ppm} \mathrm{Al}$, and $5 \pm 7 \mathrm{ppm} \mathrm{Fe}$. As trace data for this standard has not been published and concentrations might vary, laser ablation inductively coupled plasma mass spectrometry was employed to determine contents of $1.21 \pm 0.01 \mathrm{ppm} \mathrm{Ti}, 53 \pm 9 \mathrm{ppm} \mathrm{Al}$, and $<3 \mathrm{ppm} \mathrm{Fe}$, which is in reasonable agreement with the EPMA data. Although light microscopy and CL indicate damage to the quartz during EPMA at these conditions, comparative measurements of quartz with higher trace content at shorter acquisition times, lower beam current, and larger beam diameter yielded similar results. This implies that even if structural damage to the quartz lattice occurs, $\mathrm{Ti}, \mathrm{Al}$, and Fe are not significantly mobilised in the process.

Hyperspectral CL maps were collected on the same JEOL instrument with an Ocean Optics QE65000 grating CCD spectrometer at $20 \mathrm{kV}, 40 \mathrm{nA}, 1 \mu \mathrm{m}$, dwell time $40 \mathrm{~ms}$, and stage step size $2 \mu \mathrm{m}$. Deconvolution of the CL spectra using the Chimage software revealed three peaks responsible for the total CL emission at energies of $1.93 \mathrm{eV}, 2.05 \mathrm{eV}$ and $2.72 \mathrm{eV}$ (Fig. 1). The latter has previously been attributed to $\mathrm{Ti}^{4+}$ centres [3] and correlates strongly with the Ti concentration determined by the EPMA point measurements (Fig. 1). In addition, a negative correlation between the $1.93 \mathrm{eV}$ emission and the Al concentration is observed by CL-EPMA (Fig. 2) and confirmed by Fourier transform infrared microspectroscopy. This CL emission has previously been attributed to non-bridging oxygen hole centre defects [4], for instance with strained and broken $\mathrm{O}-\mathrm{Si}$ bonds or $\mathrm{O}-\mathrm{M}$ bonds $(\mathrm{M}=\mathrm{Li}+, \mathrm{Na}+$ etc) as precursors. $\mathrm{Ab}$ initio calculations concluded that incorporation of $\left[\mathrm{AlO}_{4} / \mathrm{M}^{+}\right]^{0}$ defects in quartz results in 
significant structural relaxations that extend at least to the nearest $\mathrm{Si}$ atoms [5], which could explain the observed reduction of $1.93 \mathrm{eV}$ emission with increasing $\mathrm{Al}$ content.

CL spectrometry is used to determine type and quantity of defects and impurities in quartz and reconstruct growth history and crystallisation conditions. Numerous studies have been carried out to correlate characteristic CL emission bands with certain defects (see, e.g. [4], [6], [7]). The Al and Ti distribution patterns in our study are frequently not correlated and both show uneven distribution indicating fast growth from inhomogeneous melts. Only Ti displays sharp transitions and fine oscillatory zoning, which can be explained by the higher mobility of Al in the quartz lattice. The grains exhibit features characteristic to hydrothermal quartz (sector zoning) as well magmatic quartz (oscillatory zoning), indicating crystallisation in several stages at varying conditions at the boundary between magmatic and hydrothermal stages. Crystallisation most likely occurred in a quiescent magma after emplacement, which is indicated by the well-preserved clusters of similar grains [8].

[1] J. J. Donovan et al, Amer. Mineral. 96 (2011) p. 274.

[2] A. V. McGuire et al, Amer. Mineral. 77 (1992) p. 1087.

[3] W. P. Leeman et al, Microsc. Microanal. 18 (2012) p. 1322.

[4] M. A. Stevens-Kalceff, Miner. Mag. 73 (2009) p. 585.

[5] S. M. Botis and Y. M. Pan, Miner. Mag. 73 (2009) p. 537.

[6] J. Götze, Miner. Mag. 73 (2009) p. 645.

[7] A. Müller et al, Miner. Deposita 45 (2010) p. 707.

[8] O. V. Vasyukova et al, Amer. Mineral. 98 (2013) p. 98.
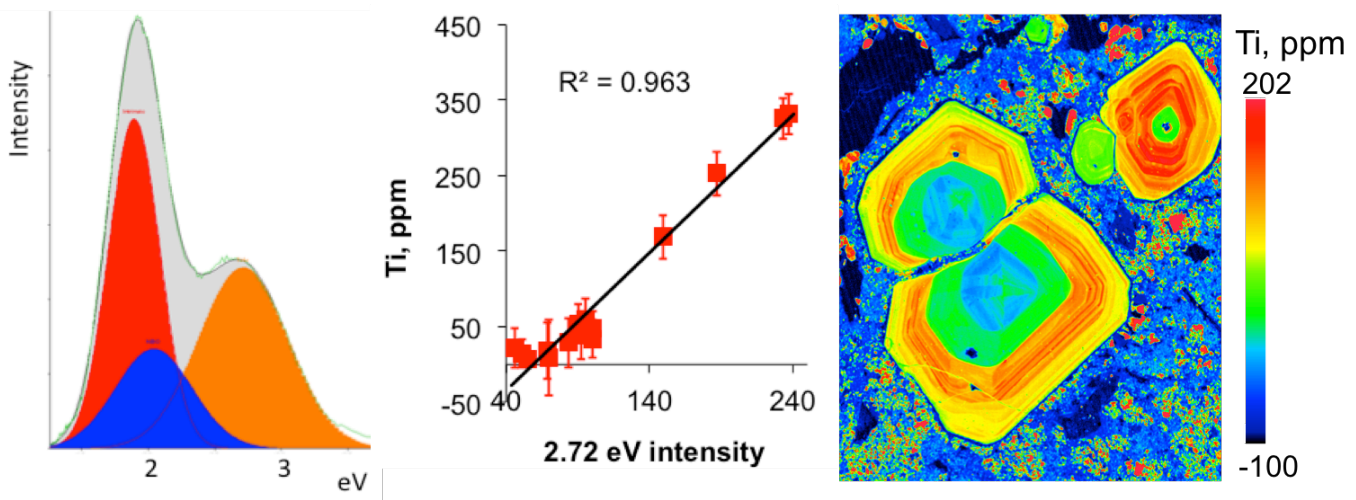

Figure 1, from left: CL spectrum with 3 Gaussian peaks fitted centering at 1.93, 2.05, and $2.72 \mathrm{eV}$; plot of 2.72 eV CL intensity vs. Ti concentration; $2.72 \mathrm{eV}$ CL map calibrated using EPMA Ti data, FOV 12x14 mm.
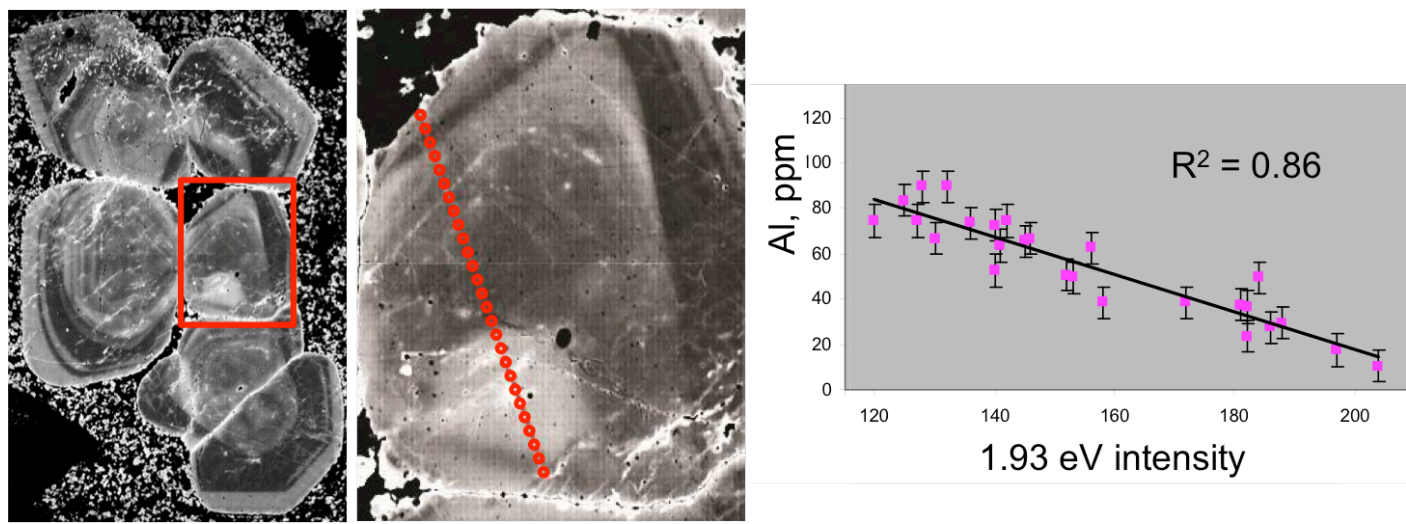

Figure 2, from left: $1.93 \mathrm{eV}$ CL map, FOV 2x3 cm; closeup of same map with EPMA spot positions; plot of $1.93 \mathrm{eV}$ CL intensity VS. Al concentration using this data. 